\title{
Analysis on Key Segment of Spot Inspection for Marine Steel Castings Ping NING ${ }^{1, a}$, Yi-jiang XIA ${ }^{1, b}$, Zhi-qiang $\mathrm{FENG}^{1, \mathrm{c}}$ and Qiong $\mathrm{HUANG}^{2, \mathrm{~d}}$ \\ ${ }^{1}$ Machinery and naval architecture \& ocean engineering College, Qinzhou University, Qinzhou, Guangxi, 535000, China \\ ${ }^{2}$ Chongqing Branch, China Classification Society, Chongqing, 401120, China anp98783@163.com, ${ }^{b} 670799125 @ q q . c o m,{ }^{\circ} 602062302 @ q q . c o m,{ }^{d}$ qhuang@ccs.org.cn
}

Keywords: Marine, Steel casting, Spot inspection, Key segment.

Abstract. Aim at the improving requirement of quality defects found on spot inspection of marine steel castings, based on the experience of on-site inspection summarized for over 20 year, the key segments of spot inspection for marine steel castings were analyzed, mainly including to study and to be familiar with inspection standards, classification rules, and other regulations; to audit casting technique documents; visual inspection of surface defects; magnetic powder testing; ultrasonic testing and etc, and the locations on marine steel castings should be paid closely attention to in spot inspection are pointed out.

\section{Introduction}

Marine steel castings are mainly used for ship stern, tail shaft pipe, horn of the rudder, rudder bearing base, marine anchors and other key places, it occupies an important place in shipbuilding industry. Marine steel castings have a strong rigidity. It's welding technique is demanded special requirements. Together with the welding quality of ship structure, the quality of ship structure and marine castings keeps a closed relationship with the shipbuilding quality and building cycle. In order to ensure the quality of marine steel castings, and to avoid the quality defects that found in later process to affect the use of the castings, to raise the building quality and cut down the construction cost, this paper summarizes the spot inspection experience over twenty years, the key segments of spot inspection for marine steel castings are analyzed.

\section{Documents preparation}

The main documents used for quality inspection of marine steel castings include "Inspection standards", "Classification rules", "Technique regulations from manufacturers" and etc.

They are as follows:

GB/T 9444-2007 Magnetic particle testing for steel castings;

GB 7233-1987 Methods for ultrasonic testing and for specifying quality levels of steel castings;

GD19-2013 Marine welding inspection guidance, China Classification Society (CCS) ;

2015 Material and welding regulation \& 2016, 2017 Revision notification, CCS.

W-06 Steel Castings, China Classification Society (CCS) 2017.05

A single or single batch inspection for marine steel castings should be carried out in accordance with the approved inspection plan. The inspection plan should includes inspecting items and testing items to be witnessed, audited and spot tested. These items mainly are chemical composition analysis (generally including the analysis to $\mathrm{C}, \mathrm{Si}, \mathrm{Mn}, \mathrm{P}, \mathrm{S}, \mathrm{Nb}, \mathrm{V}, \mathrm{Ti}, \mathrm{Cr}, \mathrm{Ni}, \mathrm{Mo}, \mathrm{Cu}$, Als and other elements intentionally added); mechanical performance testing (For stem pillars, stern pillars, rudder frame, rudder quadrant, tail shaft bracket, rudder horn, tail shaft tube and anchors with weight of more than $3000 \mathrm{~kg}$, the impact test is required ); nondestructive examination(NDE) and etc ${ }^{[1]}$.

In order to complete spot inspections of steel castings on time and in good quality, and to meet the user's inspection requirements, inspecting personnel must seriously study and understand, grasp and be familiar with the standard documents mentioned above. 


\section{Auditing casting technique documents}

Most marine steel castings are produced by unshaped single unit, the verification segment of casting technique is not exist, or the segment is not perfect ${ }^{[2]}$. But to make out a valid casting technique reasonably, it is extremely important to learn experiences from reality.

Before inspection on some important castings, it is necessary to familiar with the casting technique of the products to be inspected, and to check the melting and pouring records, heat treatment records and defects repairs records (if available) and other process control records, to understand the control conditions of the products inspected in production process ${ }^{[2]}$. To familiar with the casting technique could benefit to the inspection, and more attention could be paid to defects of the products to be inspected during casting process.

A casting technique for a stem of steel casting (single weight $>7 \mathrm{t}$ ) was shown as Fig.1. It displayed that it was not a optimum plan (may be limited by manufacture yard) of the pouring position. The casting was poured horizontally, the big end was put a semi-annular inner cold iron, five inner pouring mouths were concentrated on the upper of inner cold iron of its big end. The quality requirement for the size of inner cold iron and the technique of surface treatment are very strict, in case the unqualified control happened in production process, the serious defects from castings would be engendered. The Fig. 2 shows a partially cleaned stem bland after pouring.

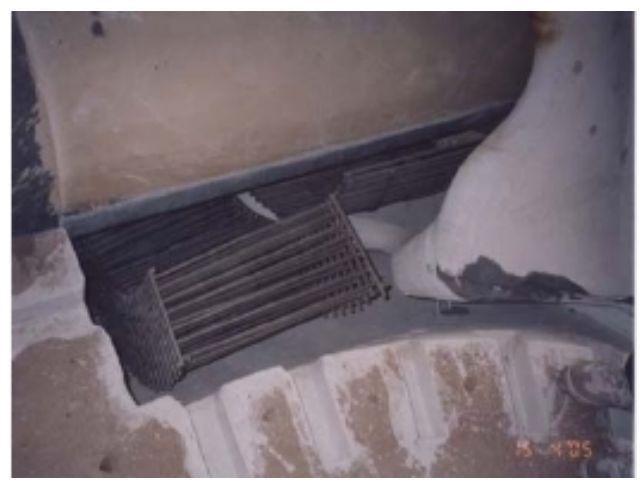

Fig.1. A casting technique for stem castings

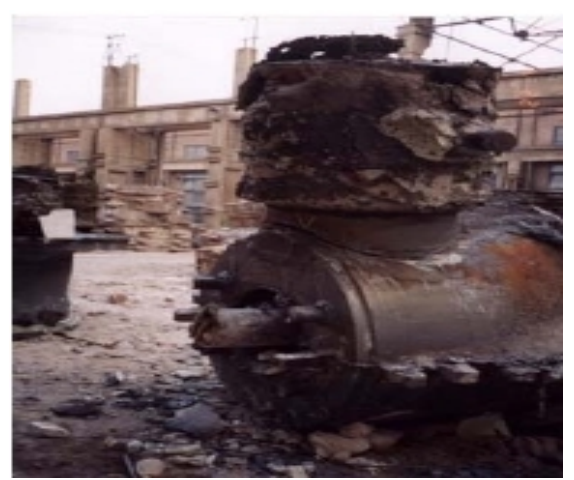

Fig.2. A partially cleaned stem blank after pouring

The important attention should be paid to positions in this technique:

Upper surface of small end, root of poured flash groove, conicalness upper surface at big end. Because during the pouring process, the negative effect caused by inner cold iron (surface oxide skin of inner cold iron produces the gas and oxidizing slag after touching with molten steel) would spread toward to the positions mentioned above along the direction of liquid steel. If pouring temperature is lower than the requirement, the melt quality of inner cold iron could not be guaranteed. The defects mentioned above could be happened partially in castings, even cracks happened, so please paid more attention to the temperature at spot inspection. A great deal of fact shows that it is difficult to remove the large area concentrated blowholes and slag inclusions after polished, as shown in Fig.3 and Fig.4.

At the end, this casting could no pass the inspection by a ship surveyor of a classification.

The improved casting technique plan for this casting should include that the big end upright, cancel inner cold iron, flash groove located at the big end, inner pouring mouth at bottom. It is not only benefit to molten steel shrinkage, but also benefit to remove the gas slag toward to flash groove, then to guarantee the casting quality of products. 


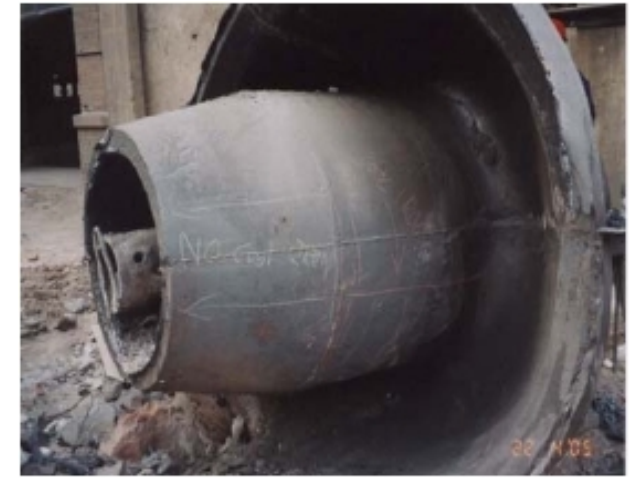

Fig.3. A partially cleaned stem blank at small end poured

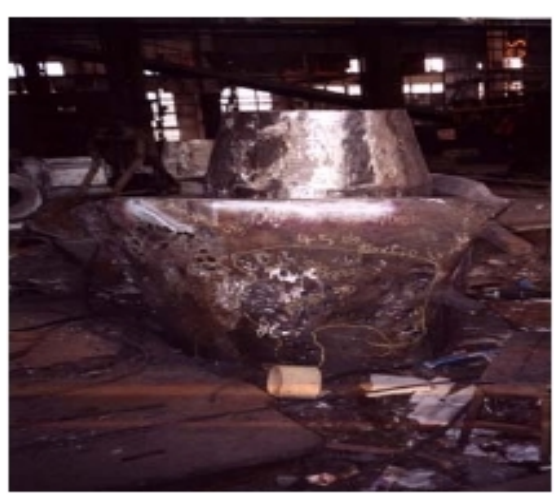

Fig.4. A cleaned stem blank of steel casting

\section{Visual inspection and magnetic particle testing}

According to the provisions of "W-06 Steel castings" by China classification society, the visual inspection for the casting to offered for approval, slight defects on casting appearance could be repaired by burnishing method. As for defects needed welding up, the factory can not be handle themselves, the surveyors of classifications must be informed to confirm the features of the defects, then welding up in accordance the required technique ${ }^{[1]}$.

The visual inspection and magnetic particle testing should be performed for high stress area. Sand inclusions and crack defects are not allowed. Other defects those affect the application performance of products (such as shrinkage hole, cold insulation, intensive blowholes, slag inclusions, etc.) are not permitted to be existed.

Magnetic particle testing is mainly used for defects detection of appearance and near surface of steel castings.

According to GB/T 9444-2007 Magnetic particle testing for steel castings, the defects can be detected by magnetic particle testing mainly include: blowholes, corrosive pitting, voids, slag inclusions, shrinkage cavity (loose), hot crack, crack, residual core support, residual inner densener, cold shut ${ }^{[3]}$.

Observed carefully under magnetic particle testing. No any suspicious magnetic mark may be let pass. There are some defects hidden below the surface. The magnetic mark is not easy to be found if no repeated magnetization and no carefully observation. Magnetic particle testing is very important especially in inspection for steel castings anchor, because there is no subsequent machining on anchor, the shape of the casting is very irregular, there is more arc bending surface and the defects near surface is difficult to be found.

In order to guarantee the quality of marine steel castings, it is suggested that the testing condition on important positions of these kind of steel castings should be in rough process status.
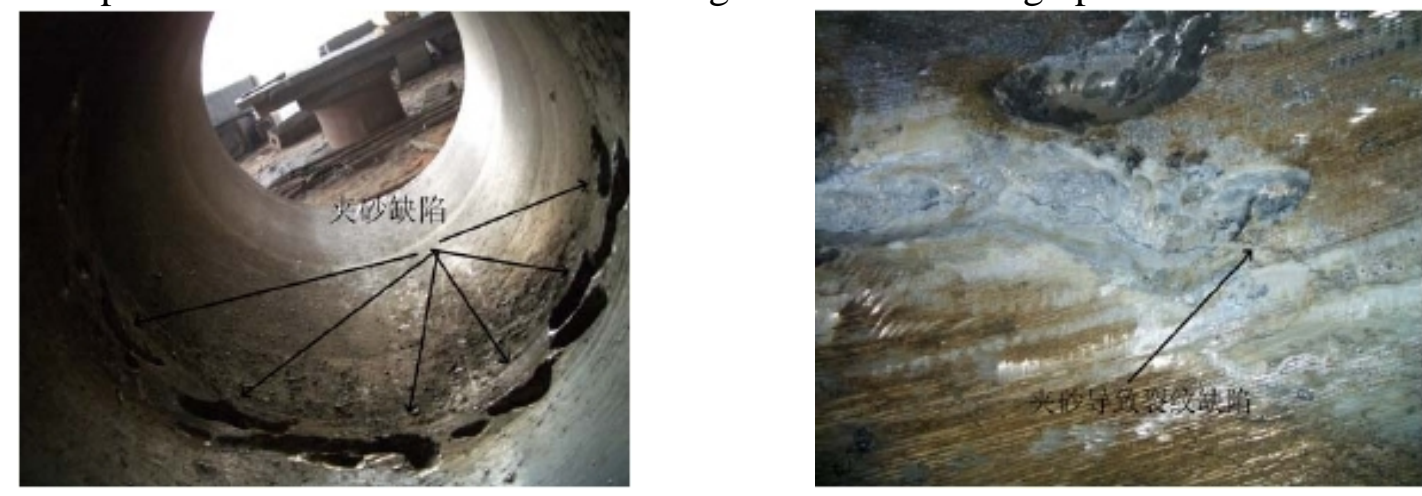

Fig.5. A sand inclusion defect on a shaft hole of a stem rough processed

Fig.6. A crack defect on a shaft hole of a stem rough processed 
For the sake of fully revealing the defects, when rough processing the machining allowance should be as less as possible, 1 3mm available. This is because some casting defects exist below the surface, it is difficult to be found by visual and magnetic particle testing. The surface roughness of casting blank and near surrounding would affect coupling and judging, as show in Fig. 5 and Fig.6, both defects are found after rough processing.

\section{Ultrasonic Testing}

Ultrasonic testing is mainly used for the detection of near surface and internal quality of castings. The inspection regulations used for marine steel castings mainly are:

GB7233-1987 Methods for ultrasonic testing and for specifying quality levels of steel castings;

GD19-2013 Marine welding inspection guidance, China Classification Society (CCS) ;

W-06 Steel Castings, China Classification Society (CCS) 2017.05.

Generally, the testing locations should be the locations as follows:

Locations appointed by approval products design drawings, pointed out by GD19-2013, locations of casting head, locations bearing high stress probably in use, and locations appointed by ship surveyors at spot inspection.

The ultrasonic testing of steel castings should be carried out after qualified appearance check, the all of substances to affect the quality of ultrasonic testing on testing surface and back of steel castings should be removed. The surface roughness of testing surface on steel castings shall be met certain requirements, such as, once the shape of a steel casting after mechanical processing impede ultrasonic testing, the testing should be made before processing ${ }^{[4]}$.

If no low wave happened or low wave damping seriously under ultrasonic testing, the result of testing was confirmed thick and big crystal particles, then re-heat treatment is allowed. After re-heat treatment, if the result of the testing keeps the same as above, the result should be judged to be unqualified.

\section{Summary}

On the basis of analysis results mentioned above, the locations should be paid closely attention to in spot inspection for marine steel castings including marine anchors are pointed out. They are: all arc locations; root locations of casting head; positions at strengthening ribs required by casting technique; locations on sand inclusion and slag inclusion, positions from marks on torch cutting and carbon arc gouging, locations at welding up and repair, locations bearing high stress probably in use, furthermore, focused on surface defects of marine anchors from welding seam at all ends of shafts or pins.

\section{References}

[1] China Classification Society (CCS) W-06 Steel Castings[Z] Beijing: CCS. 2017.05

[2] Qiong HUANG. Control for quality inspection of marine steel castings[J] China Survey 2006(10): 84-85

[3] GB/T 9444-2007 Magnetic particle testing for steel castings[S]

[4] GB 7233-1987Methods for ultrasonic testing and for specifying quality levels of steel castings[S] 